\title{
Õ-TÄHE TEEST MEIE KIRJAKEELDE ${ }^{1}$
}

\author{
VALVE-LIIVI KINGISEPP
}

\begin{abstract}
Annotatsioon. Artikkel käsitleb eesti ortograafia ajalugu, annab ülevaate pastori ja kirjamehe Otto Wilhelm Masingu (1763-1832) eesti kirjaviisi parandamise ja täiendamise ettepanekuist, $\tilde{o}$-tähele sobiva kuju otsinguist ja märgi kasutusele-

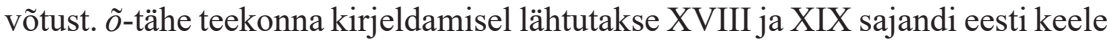
grammatikatest, Masingu teostest ja kirjadest Johann Heinrich Rosenplänterile ning Masingu kohta varem avaldatud uurimustest. Vaadeldakse, kus ja kuidas Masing oma ettepanekuid selgitas ning missuguseid arvamusi need esile kutsusid. Tuuakse näiteid $\tilde{o}$ teest meie kirjakeelde seostatuna uue kirjaviisi levikuga.
\end{abstract}

Võtmesõnad: Otto Wilhelm Masing, eesti kirjakeele ajalugu, ortograafia, vana ja uus kirjaviis

1. Ladina kirja keeltes luuakse kirjasõna ladina tähestiku abil. Eesti tähestikus on lisaks $\tilde{o}$-märk, mis eristab meie keelt enamiku Euroopa rahvaste keelte alfabeetidest. Vikipeedia andmeil on $\tilde{o}$-märk kasutusel ka portugali keeles nasaleeritud $o$ tähistamiseks. Miks ja kuidas $\tilde{o}$ meie tähestikku tekkis?

Varsti 500-aastaseks saava eestikeelse kirjasõna rajajad olid peamiselt sakslased, kes nii vaimulikes tekstides kui ka sõnaraamatutes kasutasid o-hääliku ülestähendamiseks oma alfabeedi märke $o$-d, $\ddot{o}$-d või $e$-d: oppep 'õpib', öchto 'õhtu', keik 'kõik', sest saksa keeles puudub nii õ-häälik kui ka vastav täht. Missugustest eelistustest nad lähtusid, millal kasutasid üht või teist märki, on küsimustering, millele pakub analüüsimaterjali Tartu Ülikooli eesti vana kirjakeele korpus, kus konkreetsete kasutusjuhtude

Artikkel põhineb 16. septembril 2016 Tabiveres toimunud konverentsil „Kaks sajandit $\tilde{o}$-tähega“ peetud ettekandel „Kuidas tuli $\tilde{o}$-täht eesti kirjakeelde“. 
põhjal saab usutavaid järeldusi teha. Oletada võib, et eesti $\tilde{o}$ kõlas saksa vaimuliku kõrvus $o$ ja $\ddot{o}$ vahepealse häälikuna, kirja pani seda iga teksti looja oma keeletunde põhjal, nagu nt järgmises kirikulaulus (Ross 2016: 659).

\section{Mets paksust lehte la-utab, \\ Ma ruttust rohto körkistab, \\ On keikil' kaunis nähha, \\ Keik lillikessed öitsewad, \\ Ja kaunikessed kaswawad; \\ Ni wottab Jummal tehha.}

Eesti keele häälduse eripära märkasid terasemalt XVIII sajandi eesti keele grammatikate autorid. Nii näiteks kirjutas Anton Thor Helle oma keeleõpetuse (1732) alalõigus „Eelmärkus tähtedest ja hääldusest“, et mõne sõna hääldus tuleb õppida ära ex usu ehk kuulmise järgi. Sellised on nt hunt, kot, sant, tont, palk, tootama 'tõotama', nöäl 'nõel', töeste 'tõesti', öe 'õde', sanna 'sõna', ,sest neid sõnu pole võimalik nende kahetise ebaselge kõla tõttu üksikuid vokaale välja öeldes päris selgesti hääldada“" (Helle 2006: B3a)

August Wilhelm Hupel mainib oma eesti keele grammatika sissejuhatuse alalõigus „Vom Lesen“ („Lugemisest" / „Hääldamisest"), et mõne sõna puhul puudub piisav (sks hinlänglich) märk nende õige häälduse väljendamiseks, nt hunt, kot, sant, tont, nöäl 'nõel', öe 'õde', sanna 'sõna'. (Hupel 1780: 3) Seega olid eesti keeleõpetuste sakslastest koostajad tähele pannud eesti kaashäälikute palatalisatsiooni ja $\tilde{o}$-hääliku olemasolu, mille väljendamiseks kirjas puudusid märgid, kuid alfabeedi täiendamise ettepanekut nad ei teinud.

2. Äksi kirikukoguduse pastor, kirjamees Otto Wilhelm Masing (1763-1832) ei leppinud olukorraga, kus „,kört mis paddas kedan“ ja „kõrt mis väljal künnan“" on kirjas ühtviisi ö-ga. (MN 1822: 44) 1816. aastal ilmunud raamatus ,Ehstnische Originalblätter für Deutsche“ (,Algupäraseid eesti tekste sakslastele") kirjutab ta, et eesti tähestikus puudub kaks vajalikku märki, mis vastaksid vene tähtedele $b$ ja $b l$, s.o peenendus- ehk muljeerimismärk ja üks kurguhäälikut (sks Gurgellaut) märkiv täht, praegune $\tilde{o}$. Ta leiab, et oleks vaja isegi kaht $\tilde{o}$-märki, üht kõrgemat, mis esineb $i$-diftongilistes sõnades, nagu nt oigus 'õigus', moistus 'mõistus', roigas 'rõigas', ja teist madalamat, mis esineb nt sõnades jölle 'jõle', 
sölg 'sõlg', pöl 'põll', könne 'kõne', sön 'sõnn'. (Masing 1816: 50-51) Masing hakkab sobivat märki otsima, selle kuju varieerima, ühtlasi senist kirjaviisi parandama.

XVIII sajandi Saksamaal hariduse saanud Masingu eesti keele harrastuse aluseks oli valgustuslik veendumus, et talupoegadele on vaja jagada tarvilikke seisusekohaseid teadmisi, lähtudes seejuures nende mõttemaailmast ja keelest. Varasemaid eesti keele õpetusi arvustades leiab ta, et „mitte grammatika ei tee keelt, vaid keel ise teeb grammatika“ (Kirjad II: 64), s.o keele grammatilised seadused tuleb leida keelest enesest, igal rahval on õigus kõnelda ja haridust saada emakeeles.

Eestlastel oli tema arvates vaja ühist põhjaeestimurdelist kirjakeelt, sest reeglipärane kirjakeel on teadmiste levitamise ideaalvahend. Eesti keelt oli tema meelest raske õppida, õige keele omandamine võtab aega. Oma kogemustest kirjutas ta enesekriitiliselt sõber Johann Heinrich Rosenplänterile, ajakirja „Beiträge zur genauern Kenntniss der ehstnischen Sprache“ („Lisandeid eesti keele lähemaks tundmaõppimiseks“) väljaandjale: „Varsti saab sellest 30 aastat, kui vägagi tähelepanelikult olen püüdnud keelt ära õppida - ja, Jumal! kui tihti leian oma kõige sügavamaks alanduseks, et olen selles ikka veel käpard.“ (Kirjad I: 180) Ometi kujunes Masingust praktilises keelemehetegevuses silmapaistev eesti ortograafia edendaja, kirjaviisi parandavate artiklite autor, kirjakeele sõnavara rikastaja, ühise kirjakeele eest seisja.

Masingu praktiline eesti keele kasutus toetus Ida- ja Kirde-Eestis kõneldud murrakutele, sest ta sündis Lohusuus Torma kihelkonnas ja töötas ligi 20 aastat pastorina Lüganuse ja Viru-Nigula kihelkonnas. Masingu isa Kristian Masingu (Masick), Lohusuu abikiriku köstri sünnikodu oli Maarja-Magdaleena kihelkonnas. Pärinemine idamurde alalt, kus õ-häälikut on sõnades rohkem kui mujal Eesti murretes - mine õtsekõhe üle orase - võis olla üks põhjusi, miks Masing õ olulisust keeles märkas ja sellele kirjasõnas tähistust otsima hakkas. Oma sõnastiku proovivihiku eessõnas kirjutab ta, et kuna on pärit pooleesti perekonnast, on ta kõnelenud eesti keelt (seega kodumurret) juba lapsepõlvest peale. (Kask 1970: 127) Ida- ja rannikumurde mõjul kasutab ta $\tilde{o}$-d niisugusteski sõnades, mis üldkeeles on o-ga: kõhas 'kohas', õmmetige 'ometigi', õksad 'oksad', õstma 'ostma' jt.

Ühtlasi valdas Masing paljusid keeli, teiste seas ka vene keelt, milles ó-häälik ja märk on olemas. ,Wend! mul on laddina, kreka, prantsuse 
ja itali keel ammust käes ja selge, ja wenne keelt õppisin kahhe aastaga wiggata kirjutama - tunnen weel nelli wiis tõisi keli, nenda et mõistan selgeste mis kirjutawad, et kül neid ei õska rääkida ehk kirjutada," selgitab ta Rosenplänterile. (Kirjad I: 222) Vene tähestiku võimalusi pidas Masing silmas ja tõi võrdluseks, kui oma ettepaneku teoses „Ehstnische Originalblätter für Deutsche“" avaldas.

3. Kuidas jõudis Masing tänapäevase $\tilde{o}$-märgi juurde? Tal polnud kohe head lahendust, missugune võiks õ-hääliku märk välja näha. Oma heitlikke seisukohti läkitas ta Rosenplänterile: „Mis alfabeedimärkidesse puutub, siis arvan nüüd, pärast asja hästi läbimõtlemist, ainult järgmisi vältimatuiks, ja seda peaasjalikult mitte-eestlaste pärast.“ Masing pakub nelja märki: ớ, ó, ǒ või ó, öeldes: „Kõik, mis Te siin saate, on vaid lõpetamata mõtted ja ühekülgsed, osalt hetkearvamused." (Kirjad I: 182-183) 30. novembril 1817 saadetud kirjas pakub Masing $\tilde{o}$ tarvis kaht märki: üheks on $\%$ (kahe punkti vahel püstkriips) (Kask 1976: 178) ja teiseks akuudisarnane märk + (kaldristike), mis mõeldud „raskesti hääldatavale $\tilde{o}$-le tooni andmiseks. Kui lisada sellele $\tilde{o}$-le $i-\tilde{o} i$ - siis saadakse venelaste $b l$. Kui nõustutakse tema vastuvõtmisega, siis kaob $\ddot{o}$ ja $o$ ebakindel, hääldust siiski mitte abistav kasutamine.“(Kirjad I: 203)

2. jaanuaril 1818 teatab Masing, et trükkal Johann Christian Schünmann laseb Peterburis rõhumärgiga tähetüübi ( $o$ kaldristikesega) o̊ valmistada ja seni, kuni sealt saadetist oodatakse, täidab märgi aset punctum diaereseos virgulatum 'lahutav punkt kriipsukesega' ehk $\%$. Teisisõnu $o$ ja selle kohal püstkriips punktide vahel, täht, mis igal oktaavleheküljel esinevat keskmiselt 16 korda. Kuna samal ajal oli käsil Masingu teose „Pühhapäwa Wahhe-luggemissed“ trükki toimetamine, läks õ märgiga ơ esimest korda eesti trükisõnas kasutusele. Raamatu eessõnas palub autor, et see „wõeras pookstaw (\%)“ lugejat ei pahandaks, õige tähekuju on tellimisel, see pole saabunud ja ,siis wõeti hädda pärrast se Kreka-kirja tähhekenne (む) temma assemele“. (Masing 1818: IV)

Lõpliku lahendusena see Masingule ei meeldinud. 30. juulil 1818 teatab ta, et härra Schünmann annab nüüd soovitud tähtede tellimuse hoopis Braunschweigi sisse, nende seas on akuudisarnase märgiga (o-l kaldristike) tähekuju o̊, mida Masing oma käsikirjalistes tekstides kasutas elu lõpuni, nagu väidetakse kirjavahetuse kommentaariumis (Kirjad I: 209). Huvitavat teavet lisas Tabivere konverentsil Fred Puss oma ettekandes ,, o-tähe kasutusele võtmisest luteri koguduse meetrika- ja personaalraamatutes Eesti 
eri paikades", tuues esile Masingu sissekanded, milles ta on eri aegadel kasutanud kolme õ-märki.

Tänapäevase $\tilde{o}$-märgi juurde jõudmisest kirjutab Masing 14. juulil 1819 dateeritud kirjas. Ta oli „Wanna-seädusse-aja sündinud asjade“ trükkimiseks sõlminud lepingu Schünmanniga ja keeldunud kasutamast märki $\%$. Siis tulnud ta juurde trükikoja laduja Michel (Carl Michler), „üks tragi mees“, mõttega panna $o$ peale kreeka tsirkumfleks. Samas tehti katset ja täht $\tilde{o}$ nägevat suurepärane välja. „See märk on parem kui $\delta$, sest viimane ajab kirja kirjuks.“ (Kirjad II: 120) Niisiis võiksime $\tilde{o}$-tähe sünnipäevaks pidada 14. juulit 1819. Paraku on Masing võib-olla eksinud kuupäevaga, nii et kirjeldatud sündmus leidis aset Tartus Schünmanni trükikojas kas mainitud 14. või siis 15. juulil. (Kirjad II: 122) Lisada tuleb ka, et diakriitiline märk $o$ kohal, tsirkumfleks või tilde 'lainjas märk' esines trükitekstides kas kujul $\sim$ või $\sim$.

4. Missuguseks kujunes $\tilde{o}$-märgi käekäik Masingu eluajal, sellest saab lugeda Arnold Kase kirjutistest „Mõni sõna $\tilde{o}$-tähe tarvituselevõtust“ (Kask 1932: 115-119) ja „Kuidas tuli õ-täht eesti keelde“(Kask 1976: 177-180).

Masing pidas vajalikuks oma kirjaviisi muutvaid ettepanekuid üksikasjalisemalt tutvustada. Ta avaldab 1820 brošüüri „,Vorschläge zur Verbesserung der Ehstnischen Schrift“(,Ettepanekud eesti kirjaviisi parandamiseks"), milles näitab näidete toel, et $\tilde{o}$ on vajalik sõnade tähenduste eristamiseks: kõrts ja korts, tõe (sõnast tõsi) ja töe (sõnast töö), kõrw ja korw. Brošüür oli pühendatud Kuressaare Eesti Seltsile ja Tartu Eesti Õpetatud Seltsile ning Masing arvas, et tema poolt tarvitusele võetud $\tilde{o}$-märk on leidnud eestlaste poolt kõikjal heakskiidu. Ometi ei jäänud kriitilised arvamused tulemata. Nii ilmusid 1821. aasta Beiträges arvustavad märkused Kuusalu pastorilt Jacob Anton Hirschhausenilt artiklis „Ueber einige Vorschläge zur Verbesserung der ehstnischen Orthographie“ („Mõnedest eesti ortograafia parandusettepanekuist"). Hirschhausen möönab, et eesti keeles on eriline häälik, mis kõlaliselt on $o$ ja $\ddot{o}$ vahel, olles lähemal $o$-le kui $\ddot{o}$-le, ja mida võiks nimetada tumedaks $o$-ks. Uue märgi tarvitamine toovat segadust, sest seal, kus enne oli tarvitusel kaks tähte $(o, \ddot{o})$, tulevat nüüd tarvitada ühte.

Alust vastuvaidluseks pakkus muu hulgas asjaolu, et Masing kasutas oma kodumurde mõjul $\tilde{o}$-d ka sõnades, kus mujal Eestis oli $o$, ja Hirschhausen toob selliste näiteid: ostma, kohhe, otse. Saaremaa superintendendilt August Heinrich Schmidtilt ja Kuressaare Eesti Seltsilt saadud kirjas 
lükatakse $\tilde{o}$-tähe vajadus tagasi põhjendusega, et $\tilde{o}, \ddot{o}$ ja $o$ kasutamisel on suured lokaalsed erinevused, mille tõttu häälikute piinlikult täpne märkimine oleks lugejale osalt häiriv, osalt ülearune (Kirjad II: 277 jj). Tartu Eesti Õpetatud Seltsi seisukoht $\tilde{o}$ suhtes saabus Masingule pika ootamise järel, aga oli üle ootuste soodne mitme ta uuendusettepaneku koha pealt. (Kirjad III: 18)

Masingu ettepanekut toetas elavalt sõber Rosenplänter, kes Beiträge artiklis „Vorschläge, die ehstnische Orthographie betreffend“ („Ettepanekud eesti ortograafia kohta“, 1821: 47-75) pooldas põhimõtet, et iga keeles leiduva hääliku jaoks peaks kirjas olema vastav märk, seega ka $\tilde{o}$ jaoks. Rosenplänter avaldas Beiträges Masingu andmetele toetuva loetelu sõnade kohta, kus õ-d tuleks tarvitada (Rosenplänter 1822: 145-148).

Arvamuste vahetus jätkus, nii et Masing avaldas 1824 oma teise brošüüri „Beitrag zur Ehstnischen Orthographie“ („Lisandus eesti ortograafiale") eesti kirjaviisi parandamise ettepanekutega. Selles kaitses ta $\tilde{o}$-märgi vajalikkust, toonitades selle sagedast esinemust.

Masingu brošüür kutsus esile uusi arvamusavaldusi, milles kritiseeriti ta keelelisi ettepanekuid, aga $\tilde{o}$-ettepanekusse suhtuti juba täiesti heatahtlikult (Kask 1932: 118). Arnold Kask refereerib Rannu pastori Wilhelm Friedrich Steingrüberi brošüüris „Bemerkungen über O. W. Masing's Beitrag zur ehstnischen Orthographie“ (,Tähelepanekuid O. W. Masingu raamatu kohta „Lisandus eesti ortograafiale“““”, 1826: 10) toodud täiendust: „Kaksiktäishäälikute õe, õi kõrval puudub (Masingul) $\tilde{o} u^{2}$, mis esineb nii paljudes sõnades, nagu näiteks nõu, jõud, põud jt.“ (Kask 1932: 118)

Samuti kirjutab Kask, et Masingu ettepanekute varasem kritiseerija Hirschhausen on oma kirjutises ,Ausführliche Anzeige und Beurtheilung der Schrift: Beitrag zur Ehstnischen Orthographie von O. W. Masing“ („O. W. Masingu raamatu „Lisandus eesti ortograafiale“ üksikasjalik tutvustus ja hinnang“, 1827: 10) veendunud $\tilde{o}$ tarvilikkuses ja peab $\tilde{o}$ kasutuselevõttu praost Masingu vaieldamatuks teeneks (Kask 1932: 118).

5. Praktikas hakkas Masing tänapäevast $\tilde{o}$-tähte kasutama oma ajalehes Marahwa Näddala-Leht (MN 1821-1823, 1825) ja raamatus „Luggemise lehhed“"(1821a). Kirjades Rosenplänterile jutustab ta enda kui rahvakirjaniku rasketest vintsutustest väljaannetele tsensuuri- ja trükiloa saamisel. Ta pidi tõrjuma etteheiteid, mis puudutasid nii teoste sisu kui ka keelt. 13. jaanuari 1821. a kirjas teatab ta: ,Täna jõudsid siia hea otsuse eelteated,

2 Arnold Kase märkus: „Masing tarvitab õu asemel eu-diftongi, näit. leug, peud jt.“ 
üks Riiast, teine Peterburist. Nädalaleht hakkab ilmuma ilma talurahvaseaduse elluviimise komisjoni aprobatsioonita, s.t aadlitsensuurita, ja minu lugemistahvlid võivad ilmuda nii, nagu nad olin kavandanud, ma ainult ei tohi neile muid sententse panna kui just need, mis venekeelsetele tahvlitele on võetud. - Sellest pole häda, kui minu elementaarõpetus ainult ilmuks." (Kirjad III: 15)

Ja tõesti, 1821 ilmus Masingu 20-leheküljeline brošüür „Õppetus kuida neid luggemise lehti kassuga prukida“, mis sisaldas juhiseid, ,pohkstawide näitmisest". Neis on öeldud, et koolmeister õpetagu häälduses selget vahetegemist, mis on i ja j, g ja k; ö ja õ: oi, öi ja õi. Järgneb arutlus: „Tännini on makele abd, ja makele kirri weel aina seggane ja polik, egga weel poleltki täieline olnud. Pudus weel peälegi seie ajani hopis üks pohkstaw meie awitsas ja kirjas. Waene luggu! mis üllewägga waewa teeb, ja kirja ja luggemist liastegi seggab. Sesinnane pohkstaw, mis weel pudus olli, on sesamma $\tilde{\mathbf{o}}$, mis neist luggemise lehtedest tunda sate." (Masing 1821b: 6)

Marahwa Näddala-Lehhe esimese aastakäigu rubriigis „Kirja ja õppetuse asjust" tutvustab Masing oma lugemislehti, õpetades, ,,kuida neid lehti kassuga prukida, ja kuida luggemist waewata, ja waewamata õppetada.“ (MN 1821: 59) Ta lisab samas, et lehtedega on kaasas „sadda wallalist pohkstawi, kaardi pabberi peäle trükitud, ja kui pissikesed kaardikesed leigatud, et lapsed nendega kõikisuggusid sõnnu wõiwad kokkoseata; ja nellikümmend seddasammasuggusid numrid“.

Oma õpetuses, kuidas lugemise lehti kasuga pruukida (1821b), annab Masing koolmeistritele nõu ka selle kohta, kuidas lapsi tulusalt kirjutama õpetada, mainides eeskujuna „Inglismaa mehi“ ja koole, kus õpetusviisi rakendatakse. Masing pidas silmas (vt nt Kirjad III: 20 jj) uuenduslikku lugema ja kirjutama õpetamise meetodit, mis lähtus XIX sajandi algul tegutsenud pedagoogide Joseph Lancasteri ja Andrew Belli õppekorraldusest algkooli tarvis.

Kuna Masing ei piirdunud oma ortograafiauuendustes üksnes $\tilde{o}$-tähe kasutuselevõtuga, vaid soovis uusi tähetüüpe ka palatalisatsiooni ja esimesele silbile järgneva konsonandi pikkuse märkimiseks, pidas ta pinevat sõnasõda trükkal Schünmanniga, kes tema soove vajaliku kiirusega ei täitnud ja umbusaldust teenis, ning otsis Rosenplänteri abiga soodsamaid kontakte Pärnu trükkali Marquardtiga. Näiteks 20. juuli 1821. a kirjas selgitab Masing üksikasjaliselt oma soove: „Tähte $\tilde{o}$ võib ühele oktaavleheküljele cicero kirjas keskmiselt 16 korda arvestada; aktsentueeritud 
silpe [vokaalil rõhumärk, et märkida järgneva konsonandi pikkust] 12 kuni 15, subskribeerituid [vokaali all punkt, et märkida järgneva konsonandi palatalisatsiooni] 6-8. Kui matriits on kord juba tehtud, siis võib ju saada nii palju tähti quantum satis 'kui palju vaja', parem rohkem kui vähem. Tsirkumfleks 'õ-tähe looge' on saadetud kirjaproovis nr 29 küll pisut kohmakas, sellest hoolimata võiks sellega ikkagi arvutusraamatu trükkimist alustada." (Kirjad III: 64) Tuleb lisada, et $\tilde{o}$-tähe õiget kasutust eri trükikodade väljaannetes pidas Masing väga oluliseks. Nii näiteks küsis ta Rosenplänterilt 17. septembri 1820. a kirjas: „.. kus trükitakse tõlge varjusurnute kohta? Hoidke ära, et õ ja ö ei põhjustaks trükkimisel eksitusi.“ (Kirjad II: 268)

Marahwa Näddala-Lehhe teises aastakäigus peab ta vajalikuks eestikeelsele lugejale pikemalt selgitada oma kolme kirjaviisi parandamise ettepanekut: $\tilde{o}$ tarvitamise vajalikkust sõnade tähenduse eristamiseks (töe jures on waewa, õe surma pärrast nuttan); täpikest vokaali all, mis märgib järgneva konsonandi palatalisatsiooni (palka saab orri, palka wean metsast), ja rõhumärki vokaali peal, mis toob esile järgneva konsonandi pikkuse (kanna pessas on munna, kánna tagga kánnus). (MN 1822: $44 \mathrm{jj}$ )

6. Võib arvata, et Masingu eluajal $\tilde{o}$-hääliku märkimise vajadust küll tunnistati ja teoreetiliselt selle märgiga nõustuti, kuid praktikas jäädi kauaks kinni senisesse traditsiooni. Isegi Kuusalu pastor Eduard Ahrens, uue kirjaviisi rajaja, ei vaimustunud Masingu ortograafiaettepanekuist. Ta nimetas $\tilde{o}$-d segaseks häälikuks, ebapuhtaks (sks unrein) o-ks. (Ahrens 1843: 24)

Oma grammatika teise trüki (1853) ortoeepiaosas esitab Ahrens eesti keele 8 vokaali, $\tilde{o}$-d nende seas ei ole. $\ddot{o}$ hääldust iseloomustades mainib ta, et pika $\ddot{o}$ ees häälduv o muudab selle ebapuhtaks, nt rööm, hööruma, löötsutama, öönes, pöön. Lühike ö olevat alati ebapuhas, nimelt sulanduvat kaksikhäälik oö enam-vähem üheks häälikuks, mis kõigub $o$ ja $\ddot{o}$ vahel. Teda saavat ära tunda sõnades pöld, pölw, löhki, köht, töstma, wötma, lödw, öppima jt. Sellise, nii-öelda kokku sulanud ja koos häälduva ö̈-na kujutleb Ahrens eesti ó-häälikut. (Ahrens 2003:94)

Ortograafiapeatükis mainib Ahrens, et Masing võttis kirjas kasutusele kolm uut märki, sealjuures ,ebapuhta $\ddot{o}$ märkimiseks sirkumfleksi (põld) [---]. Rahvaraamatutes on äärmisel juhul õ kasutatav, kuna see vähe silma torkab [---]“ (Ahrens 2003:108). Esimeses uues kirjaviisis kirjutatud 
raamatus, Gustav Heinrich Schüdlöffeli teoses „Toomas Westen, Lapo rahwa uso ärataja Norra maal“" (1844) on ka õ kasutusel.

Friedrich Robert Faehlmann ja Friedrich Reinhold Kreutzwald hakkasid $\tilde{o}$-d 1840. ja 1850. aastail oma kirjutistes tarvitama. Asjaliku ülevaate selle kohta andis 16. septembril 2016 Tabiveres toimunud konverentsil „Kaks sajandit ó-tähega“ Kersti Taal ettekandega „Eesti keele küsimus Fr. R. Kreutzwaldi kirjavahetuses“". Arnold Kask on esile toonud keeleliselt edumeelseid eesti koolmeistreid, kes tõlkisid eesti keelde rahvaraamatuid, nagu näiteks Caspar Franz Lorenzsonni ja tema ,Jenowewa“ tõlget (1841), „,kus ei tarvitata mitte ainult Masingu soovitatud õ-d, vaid ka palatalisatsiooni- ja vältemärki“. (Kask 1976: 179) Ka Suve Jaan ehk Johann Sommer tarvitanud $\tilde{o}$-d oma teostes. Samas lisab Kask, et küsimus, kuidas $\tilde{o}$-täht kirjakeeles levis, nõuaks eriuurimust. Missuguseks kujunes uue kirjaviisi kasutusele tulek ja seega õ käekäik, selle probleemistiku võttis ta põhjaliku analüüsi alla oma hilisemas uurimuses ,Võitlus vana ja uue kirjaviisi vahel XIX sajandi eesti kirjakeeles“ (1958). Üksikasjalise pildi o-tähe esinemusest XIX sajandi trükisõnas saab huviline Tartu Ülikooli keelekorpustest. Loomulikult nõuab see pühendumist.

Uue kirjaviisi tarvitusele tulek võttis aega, nii muutus ka $\tilde{o}$-tähe kasutamine kirjalikes tekstides üldiseks suurel määral alles pärast seda, kui Eesti Kirjameeste Seltsis otsustati 1872 Jakob Hurda ettepanekul kasutada seltsi väljaannetes ainult uut kirjaviisi ja sellega seotult siis ka õ-tähte. Markantse näite vana püsimise kohta pakub Johann Voldemar Jannseni eestvõttel 1869 trükitud I üldlaulupeo noodivihik (Eestirahwa ..), milles meie praeguse riigihümni sõnad algavad kujul „Mo issama, mo önn ja rööm“. Loodame, et laulumehed hääldasid sõnu mitte trükitud kirjapildi järgi, vaid nii, nagu need emakeeles kõlasid.

\section{Kirjandus}

Ahrens, Eduard 1843. Grammatik der Ehstnischen Sprache Revalsches Dialektes. Erster Theil: Formenlehre. Reval.

Ahrens, Eduard 1853. Grammatik der Ehstnischen Sprache Revalschen Dialektes. Erster Theil: Formenlehre. 2., umgearbeitete Auflage. Reval: Kluge und Ström.

Ahrens, Eduard 2003. Eesti keele Tallinna murde grammatika. Esimene osa: vormiõpetus. Tlk. Kristiina Ross. Teine osa: lauseõpetus. Tlk. Kristi Mets, Kristiina Rebane, Mailis Salvet. - Uue ajastu misjonilingvist. Eduard 
Ahrens 200. Koost. ja toim. Kristiina Ross. Eesti Keele Instituut. Tallinn: Eesti Keele Sihtasutus, 75-429.

Eestirahwa $=$ Eestirahwa 50-aastase Jubelipiddo-Laulud. 1869. [Koost. Johann Voldemar Jannsen.] Tarto Wannemuine-selts.

Helle, Anton Thor 1732. Kurtzgefasste Anweisung zur Ehstnischen Sprache, in welcher mitgetheilet werden I. Eine Grammatica. II. Ein vocabularium. III. Proverbia. IV. Ænigmata. V. Colloquia. Halle: Stephan Orban.

Helle, Anton Thor 2006. Lühike sissejuhatus eesti keelde 1732. Saksa keelest tlk. ja järelsõnad kirj. Annika Kilgi, Kristiina Ross. Tallinn: Eesti Keele Sihtasutus, B3a.

Hirschhausen, Jacob Johann Anton 1821. Ueber einige Vorschläge zur Verbesserung der ehstnischen Orthographie. - Beiträge zur genauern Kenntniss der ehstnischen Sprache XIII, 20-21.

Hirschhausen, Jacob Johann Anton 1827. Ausführliche Anzeige und Beurtheilung der Schrift. Beitrag zur Ehstnischen Orthographie von O. W. Masing 1824. Reval: Johann Herrmann Gressel.

Hupel, August Wilhelm 1780. Ehstnische Sprachlehre fuer beide Hauptdialekte, den revalschen und doerptschen; nebst einem vollstaendigen Woerterbuch. Riga und Leipzig: Johann Friedrich Hartknoch, 3.

Kask, Arnold 1932. Mõni sõna õ-tähe tarvituselevõtust. - Eesti Keel 4, 115-119.

Kask, Arnold 1958. Võitlus vana ja uue kirjaviisi vahel XIX sajandi eesti kirjakeeles. Eesti NSV Teaduste Akadeemia. (= Emakeele Seltsi toimetised 2.) Tallinn: Eesti Riiklik Kirjastus.

Kask, Arnold 1970. Eesti kirjakeele ajaloost I. Tartu Riiklik Ülikool, eesti keele kateeder. Tartu.

Kask, Arnold 1976. Kuidas tuli õ-täht eesti keelde. - Keel, mida me uurime. Koost. Mart Mäger. Tallinn, 177-180.

Kirjad $=$ Otto Wilhelm Masingu kirjad Johann Heinrich Rosenplänterile 18141832. I (1814-1818), 1995; II (1819-1820), 1996; III (1821-1823), 1996. Koost. Leo Anvelt, Eva Aaver, Heli Laanekask, Abel Nagelmaa. Tartu: Eesti Kirjandusmuuseum.

Masing, Otto Wilhelm 1816. Originalblätter für Deutsche. Dorpat, 50-51.

Masing, Otto Wilhelm 1818. Pühhapäwa Wahhe-luggemissed. Tartu.

Masing, Otto Wilhelm 1820. Vorschläge zur Verbesserung der Ehstnischen Schrift. Dorpat.

Masing, Otto Wilhelm 1821a. Luggemisse lehhed. Tarto: J. C. Schünmann.

Masing, Otto Wilhelm 1821b. Õppetus kuida neid luggemise lehti kassuga prukida. Tartu: J. C. Schünmann.

Masing, Otto Wilhelm 1824. Beitrag zur Ehstnischen Orthographie. Dorpat: Schünmann.

MN = Otto Wilhelm Masing 1821-1823, 1825. Marahwa Näddala-Leht. Tartu, Pärnu. 
Rosenplänter, Johann Heinrich 1821. Vorschläge, die ehstnische Orthographie betreffend. - Beiträge zur genauern Kenntniss der ehstnischen Sprache XIII, 47-75.

Rosenplänter, Johann Heinrich 1822. Welche Wörter mit einem õ geschrieben werden müssen. - Beiträge zur genauern Kenntniss der ehstnischen Sprache XIV, 145-148.

Ross, Kristiina 2016. Eesti filoloogia sünd ja kirikulaulude tõlked. - Keel ja Kirjandus 8-9, 652-668.

Steingrüber, Wilhelm Friedrich 1826. Bemerkungen über O. W. Masing's Beitrag zur ehstnischen Orthographie von einem Freunde der ehstnischen Sprache. Pernau: J. G. Marquardt. 


\title{
The journey of the letter $\tilde{o}$ into written Estonian
}

\author{
VALVE-LIIVI KINGISEPP
}

The article explains that the pastor of Äksi, the writer Otto Wilhelm Masing (1763-1832), proposed in his Ehstnische Originalblätter für Deutsche (Original Estonian texts for Germans) (1816) that a separate letter, not included in the standard Latin alphabet, be taken into use for the Estonian $\tilde{o}$ sound. Masing hailed from the eastern Estonian dialect region, where the $\tilde{o}$ sound is more common than in other dialects. This could be one of the reasons why Masing noted the importance of $\tilde{o}$ in Estonian and began searching for a way to mark it in writing. Masing knew Russian, which has the $\tilde{o}$ sound and a corresponding letter for it, and indeed made his suggestion following the example of Russian. On the basis of Masing's letters to J. H. Rosenplänter, the article describes the search for a suitable form for the letter intended to denote the $\tilde{o}$ sound. The article examines how Masing explained his suggestions for the improvement of the Estonian orthography in his German-language writings and the criticism that these suggestions received from his contemporaries. The critical or supportive reviews of J. A. Hirschhausen, W. F. Steingrüber, and J. H. Rosenplänter are summarized, attention is given to the opinions of the founder of the new orthography Eduard Ahrens, and examples are given of the journey of the letter $\tilde{o}$ into written Estonian as connected to the popularization of the new orthography in the 19th century. The $\tilde{o}$ sound in Estonian was first published in the form $\sigma$ in O. W. Masing's Pühhapäwa Wahhe-luggemissed (1818). In July 1819, the typesetter Carl Michler suggested to Masing the form $\tilde{o}$, which is still in use today.

Keywords: Otto Wilhelm Masing, history of written Estonian, orthography, new and old orthography

\author{
Valve-Liivi Kingisepp \\ Tartu Ülikooli emeriitdotsent \\ Emakeele Seltsi auliige \\ valve@neti.ee
}

